\title{
Increasing the Brand Awareness of Go China Using a Promotional Video
}

\author{
Gozali, M \\ English Department, Faculty of Letters, Petra Christian University, Siwalankerto 121-131, Surabaya 60236, East \\ Java, INDONESIA \\ E-mail:m11414029@john.petra.ac.id
}

\begin{abstract}
Asia Holiday Tour \& Travel is a travel agency based in Surabaya on Jalan Indragiri No. 12-18 \#9. It focuses more on tour package selling especially throughout Asia. Asia Holiday has a main project called Go China that offers many destinations to China. Go China's target market is Surabaya people, middle to high class, and 40 years old and older. Asia Holiday's competitors are ATS Vacations and Golden Rama. The main problem of Asia Holiday is that they only have brochures to promote and market their tour products which not so effective. As a result, the selling of Go China tour packages rarely achieves its maximum number. A promotional video is the best solution for Asia Holiday to increase the brand awareness of Asia Holiday. It is an animation video and as a representative in explaining about Go China to the target market.
\end{abstract}

Keywords: Business communication, brand awareness, promotional video

\section{INTRODUCTION}

During my 3-month internship in Asia Holiday Tour \& Travel, I found a problem which was there were almost a hundred travel agencies all around Indonesia signed up in the Asia Holiday official website. It means that those travel agencies could actually sell Asia Holiday's tour products including Go China and could get a commission from Asia Holiday. Unfortunately, in the reality, there were only almost 20 travel agencies that actively sell Asia Holiday tour products. Moreover, there were some cases that some tour packages were not sold out so that Asia Holiday must return the seats to Singapore Airlines.

Actually, the travel agencies and the staffs that can sell those products would be given a comission for each seat. On one side, Asia Holiday provides only brochures to be used to sell the products. For instance, in an exhibition, Asia Holiday provides so many brochures which consisted the tour package's schedule and more just like an itinerary. As what I have experienced during my internship period, there are several schedules which are not sold out, even only has 10 guests for 25 seats. I think it must be something wrong or lacking of something which makes other travel agencies feel difficult in selling Asia Holiday's products. This is actually a big opportunity for Asia Holiday to solve this problem and get more customers and profit from at least those 20 active travel agencies. By providing an efficient and useful sales kit to be used by Asia Holiday and other travel agencies, which will increase the brand awareness of Go China and could make Asia Holiday and other travel agencies sell Go China tour packages easier.

Thus, I decided to provide a solution to solve the problem as my Business Communication Final Project. Providing a sales kit to increase the brand awareness about Go China will help Asia Holiday and other travel agencies to sell Go China products. I will make a 2-minute promotional video about what Go China is, the benefits and advantages that guests will get if they buy Go China products, the tourism places in China, and pictures from previous Go China tours. By having this promotional video, the expectation is that the more people and potential clients will have a strong impression that whenever they are thinking about to go to China, they will directly remember Go China. Moreover, the video is also a representative to explain what Go China really is and the benefits. This promotional 
video will be uploaded through official website of Asia Holiday, applications of Go China and some social media, such as Facebook, Instagram, etc. In additional, this promotional video about Go China will be used by Asia Holiday and other travel agencies in sounding about Go China and promoting its products. It will consist of all the information related to Go China except tour packages available, prices and dates because those keep changing. This promotional video should be able to be used over and over not just in a year. The expectation is that the potential customers will be interested to know further about Go China after watching this promotional video, after that they will find further information through either official website, Go China's applications or social media.

How to increase the brand awareness of Go China using a promotional video? The goal is that to make Asia Holiday and other travel agencies can sell Asia Holiday's tour packages easier by increasing Go China's brand awareness. In fact, the company has not done any significant thing to handle and solve this problem. Therefore, a promotional video would be a right solution. This promotional video will be a kind of 'representative' in explaining Go China. The expectation is that Asia Holiday and other travel agencies use this promotional video as their sales kit so that more and more people will know about Go China and choose Go China to travel China.

The benefit that Asia Holiday will get from this promotional video is having a tool to introduce and increase the brand awareness of Go China and also to attract more customers to join Go China product and more travel agencies to sell Go China tour packages. First of all, Asia Holiday will own and use this promotional video as their sales kit to get more customers and travel agencies. This promotional video can be shown to the potential customers so that they will get the information relates to Go China products. The expectation is that by watching this video, those potential customers will become attracted and get some idea that Go China products are well guaranteed and the best choice to go to China. Moreover, Asia Holiday can also use this promotional video in the presentation or general meeting with other travel agencies so that they will be interested to join to sell Go China products because of the content of the video that can help them in selling the products more easily and get more commission from Asia Holiday. This video will also be posted in the Asia Holiday official website which everyone can watch in order to make more and more people know about Go China. It will be posted in the website in order to attract and get more potential customers who are looking for a tour by themselves so they can find this promotional video too without contacting any travel agency.

Secondly, the video will hopefully increase Asia Holiday' sales. Since the video will be visually appealing and designed creatively and professionally, the potential customers will even be attracted to join other Go China product not excluded the loyal customers, it is also possible to make loyal customers to join one more tour from Go China. It does not matter from what travel agencies that the customers join Go China tour because at the end, it is Asia Holiday who will get the profit too. On the other hand, the travel agencies who sell Go China products also will get their commission from Asia Holiday that will increase their income too. In conclusion, the more travel agencies that join in selling Go China products the more profit that Asia Holiday will get because the possibility to sell more is bigger too. This promotional video will be a solution and a key for Asia Holiday and other travel agencies in promoting and selling Go China products. Therefore, this promotional video will be very useful in boosting and increasing the brand awareness of Go China.

Goeldner and Ritchie (2003) described tourism as: A composite of activities, services, and industries that deliver a travel experience: transportation, accommodations, eating and drinking establishments, shops, entertainment, activity facilities, and other hospitality services available for individuals or groups that are traveling away from home. (p.6)

Go China is a tourism product because it provides a package of traveling service including the transportation, accommodation, foods, shops, etc. Asia Holiday as the coordinator of Go China considers Go China as a profitable project, moreover, other travel agents that joined in selling Go China tour packages also consider selling Go China as a chance too increase their profit. 
David A. Aaker (1996) claimed that awareness refers to how strong a brand can strongly embed in the customers or clients' minds (p. 10). It is measured in some different ways, such as from recognition, to recall, to top of mind, to dominant, etc. This Go China promotional video has to be as interesting as possible, so as to can stay in people's mind after watching the video. It is really important to leave an unforgettable message or impression to the potential customers that Go China is the only best choice for them to travel to China.

According to Walsh (2011, p.22), there are many ways to trigger target market's awareness and interest of company's product, such as:

a. informing potential buyers about product features;

b. announcing the availability of new products use;

c. demonstrating the benefits of a products use;

d. comparing a product with competing product;

e. showing how a product should be use;

f. informing potential buyers about the company's technical skills, production facilities, technical services, etc.;

g. informing purchasers about where products can be obtained;

h. announcing changes in prices, packages, labels, etc.;

i. publicizing a new brand name or symbol.

Relating to my project, there are several points that I want to show and tell to the viewers and to trigger their awareness and interest of Go China, such as:
a. Introducing the name of the product and its logo
b. Informing the benefits and facilities provided from the product
c. Emphasizing the selling point of the product
d. Informing about the contacts or how the viewers can get further information
e. Making the video as interesting as possible
f. Managing how the content structure should be shown in most effective way

\section{METHODS}

First of all, during my internship in Asia Holiday Tour \& Travel, I observed and found three problems. I chose one of them that is the brand awareness of Asia Holiday's main product that is called Go China, needs to be improved. After analyzing the problem and discussing with Asia Holiday's staff, I decided to make and provide Asia Holiday a more effective and attractive promotional tool that is an animation promotional video.

Then, I started to write the proposal and consulted it with my advisor. I gave the proposal to Asia Holiday's owner and had a meeting to discuss about the project. He accepted the proposal and gave me some suggestion for the video's content.

After that, I met my videographer to discuss more about this project and started the making of the video. I have collected the benefits of Go China which would be the content of the video. I also searched for some icons to be inputted in the video. After the content was completed, I asked one of my friend to be the narrator. Then, me and the videographer worked together to search the background music. In finishing the video I consulted it step by step with my advisor.

\section{FINDINGS AND DISCUSSIONS}

This promotional video is in a form of an animation. There are four main points that are shown in the video. First of all, a little bit explanation about Go China. It consists of only some words so that the viewers can get the main idea of it and to make it easier to understand. Secondly, the benefits or facilities that Go China gives to the clients, such as 5-star airlines, 4-star hotels, travel insurance, 20 Dollar Singapore voucher, tour guide and tour leader including its tips, full board meals, and surcharge free. Then, an icon of cheap price appears as an emphasis that Go China's clients get so many benefits with only a cheap price. The third point is about the popular and most visited of China's areas. Here, I also want to show the location of each area from China's map. It is a little bit of information or 
education for the viewers. In this part, it also shows some tourism places' photos at each area which I will get from Asia Holiday. Fourth thing is about the contact. Go China has already had some media that can be used by the potential clients to get further information, such as Instagram, Facebook, Go China's application in PlayStore and AppStore, and Go China official website. The last point I want to show is some photos of the previous tours that I got from Asia Holiday too. As a closing, Go China's logo appears.

The targeted audience of this promotional video is the potential clients from Asia Holiday and from other travel agents who have joined to sell Go China products. Those potential clients are the people who directly ask the travel agencies about China tours. The other target market of this video is all of the viewers of the video, especially those who are looking for a tour to China by them selves on the internet, such as from Go China official website, Facebook, and Instagram. Moreover, this video is also made to help other travel agencies in selling Go China. This promotional video is very useful and helpful because it consists of all the information about Go China that may not be explained by Asia Holiday or other travel agents to the potential customers. Moreover, Asia Holiday and other travel agents do not have to explain all of the information regarding to Go China verbally since it might sound so boring and potential customers may not have so much time to listen to them. This promotional video is the solution of those problems. It is so convenient to have a sales kit like this promotional video because once it is posted online, all of the people can watch it without contact any travel agents. The expectation is that the potential customers can have the understanding of Go China products and want to know further about the products, tour dates, prices, etc,. Moreover, there is a short version of this promotional video that is 60 seconds to be used for Go China's social media. The short version contains the explanation of Go China, the benefits of Go China, and find us.

There are some reasons why this video is made in a form of animation, first of all, in promoting and marketing a product, attracting attention and creating interest are the most important thing to be done. By having animated pictures and icon, it is more eye-catching and it creates the viewers' interest to watch more until the end. The language shown in the video is in Bahasa Indonesia. The narration of the video is also in Bahasa Indonesia. This video uses Bahasa Indonesia as its main language is because the target market is Indonesian senior people. The narration spoken by a woman with soft and informative voice has a purpose so that it is pleasant to be heard. The back-sound music is a kind of Chinese folk song so that it is aligned with the theme and the product promoted. So, from the beginning until the end of the video, there is a dubbed narration and back-sound music in order to make it more alive and interesting. Below, the video will be explained in more detail per part.

In the first part of the video, it is about an explanation about Go China. The purpose of this part is to introduce the product and the brand. The main goal of this promotional video is to increase the brand awareness of Go China so Go China logo has to be shown few times so that people are familiar with it and it stays on the viewers' memories. The icons used in the first part are red Chinese curtain and two iconic Chinese kids, are to create a China atmosphere. I decided to use the two iconic Chinese kids because the kids are related to the Chinese New Year culture. In the Chinese culture, when the Chinese New Year is coming, the adult people who have married give red envelopes or 'angpao' to the young people especially those who have not married yet. The two kids shown in the video is the common icon used in the red envelope or 'angpao'. Moreover, even though the impression of the icons is like a childish video, the senior people might find it attractive too, because they might think that this product would be given to their children or grandchildren. I decided to use dynamic icons is because static icons would be boring and the viewers might not be interested to keep watching the video. The words used for the explanation is a common words that are used in general so that it is easier to be understood and does not contain too many words.

The second part of the video is about the benefits Go China offers to the clients. The backsound music used in this part is the same with the first part. Also, still using a dubbed narration to explain or give more information relates to the icons shown. The reason why I chose the font style used for the word 'benefits' (see Figure 3.b.5) because it is easy to be read and not too formal style to be in tune with the whole concept. Using the same icon, a girl with Chinese costume, there are some benefits 
that are emphasized in this part. The color used in this part is similar to the first part which red is dominant to keep the Chinese atmosphere. Moreover, there are some arrows pointing upwards and moving are to make the viewers focus and feel excited to see the next part. As a product of a tourism company, Go China also offers many services as the benefits given to the clients. In this part, those benefits are shown in animated icons. The icons are colorful to keep the viewers' attention and interest.

In the third part of the video, there are 7 areas of China that are most popular and visited by Go China. The reason why I chose those 7 areas is because those places have represented China in general, from the nature, history, modernity, and culinary. The order of those 7 areas is from the owner of Asia Holiday, such as Beijing, Shanghai, Suzhou, Hangzhou, Huangshan, Jiuzhaigou, and Zhangjiajie. I chose to follow the information he gave to me because I believe he knows really well about his product, which the most popular and visited ones. In this part, there is a China map that shows the whole China. I chose to have the whole China's map to educate the viewers so that they feel familiar with it and feel like want to visit China with Go China. The China's map appears quickly in every area before the pinning scene is because I want to emphasize the pinning scene to educate the viewers. Then, there is a pin pins at the area and a Google Map of the area appears. This part is also to educate the viewers about the location of each area that is showing. Furthermore, in this part, I want the viewers' pay attention on the tourism places not the map so I chose to use the Google Map which has mainly white color that is not too eye-catching. The name of the area appears with the nickname I chose. The font style used in this part is the same with the first part that is not too formal kind of style and easy to be read. After that, there are some pictures of tourism places at the area in order to create the viewers' desire to visit the places.

The fourth part of the video is about 'Find Us'. The reason why I chose to have 'Find Us' part not in the last of the video as usual promotional video has, is to minimize the possibility of the viewers do not pay attention or stop the video before they get the information where they can find further information about Go China. Because this video is more than 2 minutes, so to avoid people get bored and do not see the 'Find Us' part, I decided to arrange it this way. Moreover, according to Walsh (2011), informing purchasers about where products can be obtained is also effective in triggering the viewers' awareness of the product. The arrangement of the icons of the applications, such as Facebook, Instagram, PlayStore, AppStore, and website, is horizontal to make it neater and more comfortable to be read.

The last part of this animated promotional video is some pictures of previous tours of Go China. There are three pictures that are from different group of tour and destinations. The dubbed narration in this part has an important role to invite the viewers to join Go China as soon as possible to have memorable tours like the people shown in the pictures. As a closing, there is Go China's logo. The reason why I put the logo in the last is to leave a memory about Go China in the viewers mind. As said in the Chapter 2, Walsh (2011) stated that publicizing a newbrand name or symbol can trigger the viewers' awareness of the product. Moreover, showing the logo or brand for few times is called memory value that can help the viewers to remember the logo and the product.

The short version of this video will be used especially for Go China's Instagram that is only 60 seconds. The short version contains the explanation of Go China, the benefits of Go China, and find us. There are some reasons why I decided to choose those points as the short versions' content. First of all, the main goal of this short version of video is to make more and more people watch and know Go China. On the other words, the goal is to increase the brand awareness of Go China through online. In the beginning of the video, there is the explanation of Go China. Then, the benefits of Go China are also shown in this version. It is in order to make the viewers interested with the benefits Go China offers. The last point is the find us part. After the viewers are interested with Go China and its benefits, they need to know where to find further information of Go China.

Secondly, the duration of the video in Instagram is limited that is only 60 seconds. To put more content to the short version of the video would make it too packed and not so enjoyable to watch. Moreover, the dubbed narration and the back sound music are the same with the long version of the 
video. The back sound music of the long version of this promotional video is already suitable with the concept that is Chinese theme. So, I decided not to change the back sound music.

\section{CONCLUSION AND SUGGESTIONS}

For my Business Communication Final Project, I decided to make a promotional video for Asia Holiday Tour and Travel, the company where I did my internship. During my internship, I found some problems which I decided to have one problem to be my final project. The problem is that there are many tour agencies join in selling Go China, yet there are some tour packages that are not sold out. Moreover, Asia Holiday Tour \& Travel only has brochures of Go China to be used in selling Go China that is not so effective. Asia Holiday has not provided a more effective sales tool like promotional video. A promotional video can be used when the travel agents have a sales call, when there is an exhibition, and to be posted through online, such as Facebook, Instagram, application of Smartphone, and Go China official website. This promotional video is really important to increase the brand awareness of Go China so that it is easier for the travel agents to sell Go China.

There are five parts of this video that are "What is Go China?", "What are the benefits of Go China?", "What are the most visited destinations of China?", "Where can the viewers get further information of Go China?", and "The documentations of previous tours?". Those parts of the video is to introduce Go China to the viewers, to create the viewers' desire to join Go China, and to trigger the viewers' action to contact Go China right after the video is finished.

There are some benefits Asia Holiday Tour \& Travel can get from this promotional video. First of all, the travel agency can get an effective promotional tool that introduces Go China to potential customers so that the brand awareness of Go China will be increased. The promotional video is made in a form of animation and made as interactive as possible. Secondly, Asia Holiday can provide the other travel agencies with a promotional tool so that they can sell Go China tour packages easier. As a result, more travel agencies will be interested in selling Go China tour packages. Moreover, this video is also can be used when there is a presentation or general meeting held by Asia Holiday with other travel agencies. Thirdly, Asia Holiday also can use this promotional video to be posted in Go China social media, such as Facebook and Instagram, Go China's application in Play Store and App Store, and Go China's official website. Having promotional video thorough online is really helpful to boost the brand awareness of Go China because it can be shared and watched by more and more people.

Finally for the next students of English Business Communication students who plan to do Business Communication Final Project, I want to give some suggestion in finishing the final project. First of all, try to search the problems of the company. Then, look for the possible solution. Talk and discuss it with the owner or the staff in the company would be really helpful. When you already have a project to do, make sure to plan and do brainstorm about the concept, content, etc. before you talk and discuss further about the project with the staff or owner. When you already have the concept, discuss it with the staff or owner. They usually have a suggestion or requests. You have to present your idea in the most effective and best way so that they would feel that this project is really important for them. As a result, they want you to do this project as soon as possible and they would pay you for this project. You can use the suggestion and advices for your project, but do not take it as it is. Think further and make your project beyond their expectation.

\section{REFERENCES}

Aaker, David A. (1996). Building strong brands. New York: The Free Press.

Boman, K., \& Raijonkari, K. "Online video as a marketing tool; A quantitative survey on video marketing habits," B.S. Thesis, Sch of Business., JAMK Univ., Findland. 2017. [Online]. Available: https://www.theseus.fi/ bitstream /handle/10024/ 127852/Boman_Kalle_\%20Raijonkari_Kalle.pdf?sequence=1\&is Allowed=y

Goeldner, C. R., \& Ritchie, J. R. (2003). Tourism: Principles, practices, philosophies. New York: Wiley. 
Mccabe, S. (2009). Marketing communications in tourism and hospitality: Concepts, strategies, and cases. Oxford: Butterworth-Heinemann.

Mill, R. C., \& Morrison, A. M. (1985). The Tourism System: An Introd. Text. Englewood Cliffs: Prentice-Hall International.

Walsh, T. (2011). Tourism promotion. New Delhi: Discovery Pub. House. 